\title{
ADQUIRIR COMPETENCIAS COMUNICATIVAS EN ELE EN UN CONTEXTO PLURILINGÜE: EL CASO DE LOS ALUMNOS DE LA FACULTAD DE ARTES, LETRAS Y CIENCIAS SOCIALES (FALSH) DE LA UNIVERSIDAD DE MAROUA
}

\author{
Patrick Toumba Haman ${ }^{1}$ \\ Universidad de Maroua (Camerún)
}

Recibido 17/08/2020 Aceptado 09/12/2020

\begin{abstract}
Z El presente artículo parte de la doble influencia recibida por los alumnos de ELE de la Facultad de Artes, Letras y Ciencias Sociales de la Universidad de Maroua, en Camerún. En efecto, se trata de una doble influencia institucional y sociológica, si tomamos en cuenta el que por una parte, cada uno de ellos ha recibido una larga formación en francés, por ser francófonos, y otra relativa en inglés, ambas siendo lenguas oficiales; por otra parte, estos alumnos entienden por lo menos un idioma local con el que han entrado en contacto desde su infancia, en el medio familiar y comunitario. ¿Cómo adquirir debidamente competencias comunicativas en castellano, idioma de su formación en los estudios superiores, en este espacio plurilingüe?
\end{abstract}

This paper is centred on the double influence received by the students of SFL at the Faculty of Arts, Letters and Social Sciences of the University of Maroua, in Cameroon. In fact, it is a double influence at institutional and sociological levels, as for in one hand, each of those learners, who are francophone speakers, has a large background in French and a relative one in English, both languages having an official status. In the other hand, each of those students speaks at least one local tongue learnt from the childhood in the family and the community. How can they easily acquire communicative competences in Spanish, their academic language, in such a highly linguistic milieu?

DOI

https://doi.org/10.15366/didacticas2020.23.007

PALABRAS CLAVE

Doble influencia; Estudios superiores; Francófonos; Competencias comunicativas. competences. 


\section{INTRODUCCIÓN}

De entrada, señalemos que África es, en palabras de Nana Tadoun (2016: [Enlace]), “un continente esencialmente políglota, donde conviven, casi siempre de modo armonioso, una plétora de idiomas intraafricanos a los que, por varias razones, se injertan pacífica o violentamente el francés, el inglés, el portugués”. De la misma manera, puede aplicarse a Camerún esta descripción lingüística, sobre todo cuando recordamos que suele considerarse este país un África en miniatura. En el medio de todas estas lenguas, el español está cobrando cada vez más peso por el número creciente de sus aprendientes. El interés de esta reflexión radica, desde luego, en la importancia, por parte de los alumnos de ELE de la Universidad de Maroua, de mejorar sus habilidades comunicativas en un espacio altamente influenciado por lenguas que más utilizan en su cotidiano.

Estructuramos dicha reflexión en tres apartados. Primero, presentaremos el sitio que ocupa el español en el sistema educativo de Camerún, en comparación con varias otras lenguas con estatutos diferentes, sin olvidar las propias lenguas maternas que ejercen un gran peso en nuestros aprendientes. Luego, nos detendremos en la doble influencia que reciben nuestros alumnos de ELE, por el francés considerado como su segundo idioma materno- el primero siendo sus idiomas locales-, por proceder ellos de la parte francófona del país y el español, el idioma de su formación académica. Esta situación crea enormes interferencias en el aprendizaje del español, como veremos, con la finalidad de dejar constancia de la dificultad de poder adquirir eficazmente competencias comunicativas en un contexto similar. En fin, haremos unas propuestas de cara a ayudar a nuestros alumnos a mejorar su comprensión y expresión, gracias al uso de los medios de comunicación y a través de actitudes más responsables como la determinación y la autonomía de las que muchos carecen habitualmente.

\section{EL SITIO DEL ESPAÑOL EN EL SISTEMA EDUCATIVO DE CAMERÚN}

El subsistema francófono, en el sistema educativo de Camerún, ofrece a los alumnos de la enseñanza general, a partir del tercer curso del instituto, la posibilidad de optar por un idioma extranjero, aparte de las dos lenguas oficiales, heredadas del sistema colonial, que son el francés y el inglés utilizados con porcentajes muy desproporcionados. Se trata de una desproporción heredada desde la presencia colonial cuando después de la derrota de Alemania en la primera Guerra Mundial y tras el Tratado de Versalles de 1919, Francia ocupó el $80 \%$ del territorio camerunés e Inglaterra el $20 \%{ }^{1}$. Desde esta perspectiva, se han

\footnotetext{
1 Por esta realidad histórica y su consecuente herencia lingüística, los habitantes de la parte anglófona de Camerún se consideran marginados. Por limitarnos tan solo al aspecto lingüístico, piensan que el bilingüismo previsto por la Constitución está siendo mal aplicado por el uso minoritario del inglés al nivel institucional. Además, el sistema judicial heredado de Francia es el que se aplica a todo el país, lo que se consi dera como un engaño del que son víctimas los profesionales de la justicia que ejercen en la zona anglófona. Esta 'injusticia' y otras más están al origen de la guerra iniciada hace unos tres años por secesionistas que reclaman la autonomía de la parte anglófona a la que denominan ‘Ambazonia'.
} 
introducido varias lenguas, el español, desde 1951 en la enseñanza secundaria, según el modelo del currículo educativo francés y en 1963 en la enseñanza superior- en la antigua Universidad de Yaundé, convertida en Yaundé I, desde la reforma de 1992 que dio lugar a la creación de otras universidades- como menciona Kem-Mekah-Kadzue (2014: 463). En el año 2010-2011, el número de los alumnos de español de la enseñanza secundaria y universitaria, en Camerún, asciende a 193.018 mil$^{2}$, según un estudio realizado por Onomo-Abena ${ }^{3}$ (2014), por lo que este país es el undécimo país del mundo y el cuarto africano con más alumnos de español, después de Benín, Costa de Marfil y Senegal. Lo cual constituye un fuerte potencial para la difusión de esta lengua.

En Camerún, esta lengua se imparte plenamente en cinco universidades públicas: Yaundé I (en el actual departamento de estudios ibéricos, iberoamericanos e italianos, desde 1963 cuando el español era un idioma optativo, y en la Escuela Normal Superior), Duala (desde 1994), Dschang (desde 1995), Maroua (en la Escuela Normal Superior desde el año académico 2008-2009 y en la Facultad, desde el 2013-2014) y en la Escuela Normal Superior de Bertoua (desde el año 2017-2018), de creación más reciente y dependiente de la Universidad de Ngaoundéré. Existe un ciclo de doctorado en estudios hispánicos en las cuatro primeras universidades. En Yaundé I, por ejemplo, cinco alumnos han leído sus tesis (el primero en 2009, Essissima Michel-Yves, el segundo en 2015, Mvondo Wilfried, el tercero en 2017, Zambo Bomba Apollinaire, el cuarto en 2019, Mbesse Akamse François Désiré y el último en 2020, Fotso Toche Rodrigue). En el mismo orden de ideas, cuatro alumnos han leído sus tesis en la Universidad de Duala (Eloundou Eloundou Girex en 2019, Loe Odile Marie Rose, Nami Leumi Agnès y Fouodji Wagoum Roseline en 2020) y dos en la Universidad de Dschang (Tchinele Daghuie Joseph Sévérant y Fomekong Narcisse en 2020). En la Unidad de Formación Doctoral 'Literaturas, Lenguas y Ciencias del Lenguaje' de la Escuela Doctoral de la Universidad de Maroua, siete alumnos se han hecho doctores en estudios hispánicos. Se trata de Hatolong Boho Zacharie (2014), Yaouba Daïrou (2017), Touotsap Tiayon Ignace (2018), Barki Simala, Donfack Sounna Anicet Christian y Koudjou Beaudelaire Collince (2019) y Develeme en 2020. Como se ha podido comprobar, en unos once años, se han doctorado dieciocho alumnos en universidades

\footnotetext{
2 Para dar cuenta del importante lugar ocupado por el español, y refiriéndose a su enseñanza en la educación secundaria, Mbarga (1995: 243) menciona que "compite con el alemán, y ocupa la tercera plaza detrás del francés y el inglés que son los idiomas oficiales". Para comprobarlo, Kem-Mekah Kadzue (2014: 364) presenta, por ejemplo, el número de alumnos de español y alemán en Camerún en los años 1999, 2001, 2003 y 2005. Según las estadísticas del Ministerio de la Enseñanza Secundaria, que nos ofrece Onomo-Abena (2016), en el año 2010-2011, hay unos 1036 profesores de de la enseñanza secundaria en Camerún, para más de 610 institutos y colegios. Es importante señalar que el contexto actual de globalización hace del continente una especie de laboratorio lingüístico, en que van enseñándose más lenguas con el paso del tiempo. En Camerún, hoy en día, si exceptuamos algunas lenguas nacionales que van introduciéndose paulatinamente en el currículo educativo, el francés y el inglés, idiomas oficiales, el español y el alemán introducidos antes de la independencia, van ganando terreno, aunque en diferentes grados, el latín, el árabe, el japonés, el portugués, el italiano, el turco y el chino.

3 Señala el autor que "la lengua española ha sido, es y seguirá siendo una preocupación tanto de los do centes como de las autoridades gubernamentales camerunesas" (2014: https://cvc.cervantes.es/lengua/ eeas/ capitulo7.htm).
} 
camerunesas, de los que hasta siete sólo para el año 2020. Muchos otros alumnos están adelantados en sus investigaciones o a punto de doctorarse, lo que es una prueba del crecimiento del español en Camerún ${ }^{4}$. Estos alumnos, antes de sacar este título, tienen la obligación de hacer una estancia en España o en cualquier país hispanoamericano ${ }^{5}$ con la finalidad no sólo de enriquecer su bibliografía en sus diferentes campos de investigación sino también de empaparse en la lengua, con el objetivo de mejorar sustancialmente sus competencias comunicativas. El mapa de la siguiente página deja aparecer las cinco universidades estatales donde se imparte español, en Facultad y/o en Escuela Normal Superior donde se forman a futuros profesores de colegios e institutos, con sus años de creación.

Conviene recordar que todos esos alumnos de ELE en Camerún, para matricularse en estudios hispánicos en la universidad, han estado en contacto con el idioma al menos durante cinco años. Desde luego, el castellano viene a equipararse con la lengua del colono, el francés en su caso, porque ambos vehículos del diálogo en el medio estudiantil han formado la personalidad de dichos alumnos. La consecuencia directa es que aparecen muchas influencias del francés y el castellano en ellos. Y por limitarnos tan solo a la influencia del castellano como lengua extranjera, es fuerte su influencia en los comportamientos de los aprendices, quienes, desde luego, se identifican mucho, en su cotidianeidad, con figuras simbólicas del mundo hispánico: son, por ejemplo, héroes históricos o de películas, a través de telenovelas que han venido invadiendo el mercado cinematográfico de Camerún, estrellas del mundo futbolístico. Todos estos ingredientes contribuyen, del mismo modo, a fortalecer y a animar a dichos estudiantes a seguir optando por los estudios hispánicos como rama de su formación académica, lo que les permite sacar diplomas tanto académicos como profesionales. Conviene señalar que su dedicación al aprendizaje y a la formación en esta lengua de Cervantes no se hace por un mero pasatiempo, pues, existen fuertes motivaciones por parte de los alumnos, entre las cuales se encuentran los objetivos profesionales, entre otros, como queda dicho. Todos estos alumnos, no cabe duda, están al tanto de las posibilidades que brinda esta lengua muy utilizada hoy en día, en Guinea Ecuatorial, Marruecos, o en la veintena de los países hispanoamericanos que la

\footnotetext{
4 El crecimiento de la enseñanza del español en Camerún tiene enormes resultados, entre ellos el nacimiento de "la literatura hispanocamerunesa cuyos pioneros son: Céline Clémence Magnéché Ndé, Boniface Ofogo, Inongo-vi- Makomé, Magloire Mol Nang, Germain Metanmo, Guy Merlin Nana Tadoun, Robert Marie Johlio y Germain Metanmo. A estos se asocian la generación de escritores emergentes como Alain Lawo-Sukam y Romuald Achille Mahop Ma Mahop" (Lawo-Sukam, 2014: 903). Conviene recordar que no es exhaustiva esta nómina de los cameruneses que expresan su talento literario en español.

5 Por la proximidad geográfica y, sobre todo, por el carácter original del español de la metrópoli, todos los doctores cameruneses han hecho más bien una estancia en España. Cabe recordar que esta práctica ha sido instituida por el que consideramos en Camerún el padre del hispanismo, jubilado en 2019, el Profesor Onomo-Abena Sosthène, ex Director del Departamento de Estudios Ibéricos, Iberoamericanos e Italianos de la Universidad de Yaundé I. Por lo general, los doctorandos financian su viaje y estancia. Existen conve nios con unas universidades españolas. Son, por ejemplo, los casos de la Universidad de Yaundé I con la de Oviedo, o de la Universidad de Maroua con la de Salamanca, entre otros. Son convenios que facilitan el acceso de los doctorandos a las bibliotecas.
} 
tienen por lengua oficial, o por su uso en negocios o en organismos internacionales, sin olvidar su paulatina extensión por el mundo, por tomar solo el caso de Estados Unidos donde se expande con mayor velocidad.

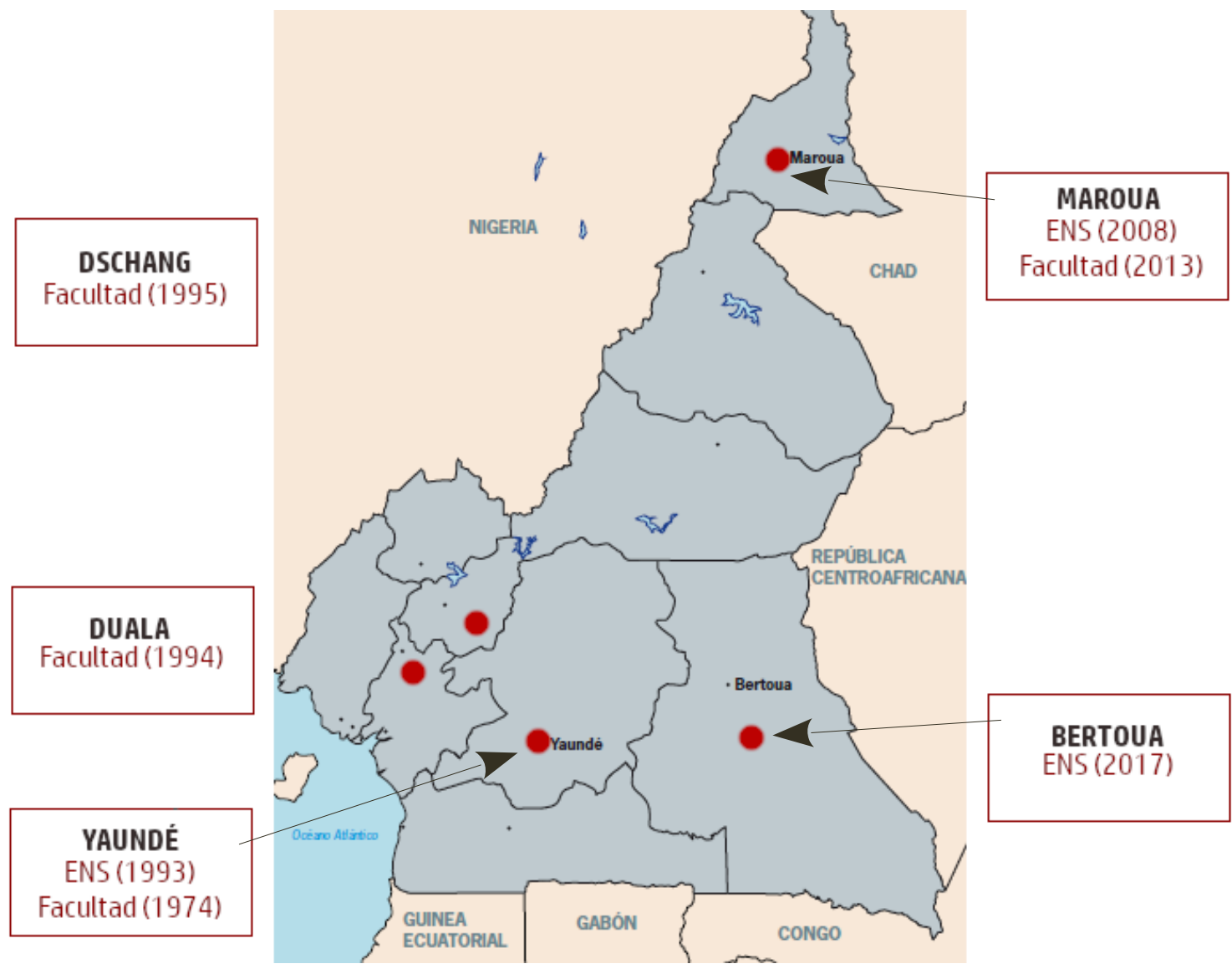

Figura 1. Mapa con la situación de cinco universidades de Camerún

Una formación completa de nuestros alumnos, hasta su llegada a las universidades, supone así la adquisición de varios conocimientos relacionados con el mundo hispánico. Ello aparece en los currículos elaborados para la enseñanza, tras las reformas del sistema educativo camerunés, con las conferencias generales de la educación de 1995 que dieron lugar a la ley de orientación escolar de 1998, donde la formación del aprendiz ha de hacerse de cara a ofrecerle una formación completa o más decente. En la mayoría de los casos, estos currículos, en la práctica, toman en cuenta la formación del individuo en todos los ámbitos para que luego este pueda estar más preparado en la sociedad. Ello se debe a la evolución de los métodos de enseñanza/aprendizaje, ya no centrados en la mera transmisión sino en el propio alumno que deja de ser un receptáculo. Ya no se trata de ofrecer conferencias magistrales a los alumnos, seguidos de ejercicios de aplicación. Esta ruptura fundamental en la naturaleza de la relación pedagógica se había introducido por Rousseau (1966), en Emile ou de l'éducation, ya que hasta entonces la pedagogía se preocupa- 
ba mucho más por la transmisión del mensaje. El mayor objetivo perseguido sería, desde luego, romper los esquemas escolásticos y tradicionales para llevar al alumno a pensar. Como menciona Giry (2002: 15), "En [las] nuevas pedagogías, se aprende primeramente a aprender, o a pensar ${ }^{6}$, y para ello es necesario concentrarse en el alumno". Es, entre otros objetivos, el perseguido por el llamado 'Approche par Compétences' (APC) ${ }^{7}$, método que sigue implementándose en el sistema educativo, a raíz de la necesidad de una reforma curricular en Camerún. Para conseguirlo, existen estrategias pedagógicas que hay que poner en marcha.

Una de estas estrategias, presentes en todo proceso de enseñanza/aprendizaje de una lengua extranjera es la toma en cuenta de las cuatro destrezas de la comunicación: la lectura, la escucha, el habla y la escritura. Las destrezas han supuesto un avance considerable en la metodología comunicativa en ELE ya que incrementan la capacidad comunicativa de los estudiantes. Conforman así el cerebro del aprendiz, ofreciéndole una conciencia que le permite reflexionar, hasta cierto grado, como un nativo de una determinada lengua, en este caso la que se aprende. En el caso de nuestros alumnos, en Camerún y específicamente en Maroua, es importante subrayar la configuración de su pensamiento, a diferencia de lo que sucedería con un nativo de España que lo hace todo en castellano, ya desde su nacimiento, donde a la hora de aprender lo hace todo de manera intuitiva, sin referencia a otro sistema. No está fuera de lugar recordar que ellos son de la parte francófona, donde con mayor grado se ha implementado la enseñanza del español como subrayamos anteriormente. Para la mayoría de ellos, entran por primera vez en contacto con esta lengua extranjera a partir del tercer curso, entre los 14 y los 16 años. Pero antes, casi todo lo que constituye su formación, hasta al menos el bachillerato, lo reciben en francés, si exceptuamos la única asignatura de inglés, que puede variar de dos a tres horas semanales dependiendo del nivel escolar, sin olvidar que gran parte de estos alumnos solo lo tienen como asignatura a partir del colegio. Por otra parte, desde su nacimiento,

6 López Reyes (2009: 2) hace una distinción entre aprender a aprender y enseñar a pensar. Enseñar a pensar tiene como finalidad el estímulo de las capacidades cognitivas de los alumnos mediante la comprensión, la codificación, la elaboración y la memorización, mientras aprender a aprender consiste en po ner al alcance del alumno una serie de instrumentos y estrategias concretas para que le sea más fácil y más productivo el aprendizaje. Varios escritores han reflexionado en lo importante que es llevar a los educandos a pensar en las prácticas de enseñanza-aprendizaje. Es el caso de Einstein, cuando afirma que "el valor de una educación universitaria no es el aprendizaje de muchos datos, sino el entrenamiento de la mente para pensar" [Enlace] o de Harris, a través de su metáfora siguiente: "Muchos estudiantes toman al estudio como un líquido que hay que tragar, y no como un sólido que debe masticarse. Luego se preguntan por qué proporciona tan poco nutrimento real" [Enlace].

7 Este método, de carácter funcional, rechaza la idea de considerar al alumno como un receptáculo y des pierta así en él la necesidad de llevarlo a descubrir sus aptitudes y a implementar sus competencias, el saber reaccionar con prontitud frente a una diversidad de situaciones. Ser competente es entonces poder poner en práctica y en el debido momento los saberes adquiridos. Ello define el tipo de ciudadano que ne cesita Camerún, no orientado hacia conocimientos empíricos, sino capaz de raciocinar. En otras palabras, los educadores que somos debemos saber asociar los saberes proporcionados por la institución con es trategias nuevas de cara a llevar a los aprendices no solo a aprender para sacar un diploma sino a aprender a razonar a lo largo de su vida. Este nuevo paradigma pedagógico forma a los alumnos tomando en cuenta las necesidades de la sociedad. 
todos están inmersos en un universo donde la práctica de un dialecto materno casi es exclusiva y obligatoria para las necesidades cotidianas. Asimismo, unos alumnos llegan a hablar perfectamente dos, tres o más lenguas nacionales, a veces, por razones de vínculos familiares o por su proximidad geográfica con otras áreas lingüísticas con las que acaban por familiarizarse. Y dentro de estas lenguas, aparece una presencia bastante importante de vocablos procedentes del francés o del inglés, consideradas lenguas más fuertes. En cualquier caso, el francés y el inglés acaban teniendo más peso en el sistema camerunés como menciona Onomo-Abena (2014: [Enlace]):

En el currículo camerunés, las lenguas extranjeras tienen primacía sobre las nacionales. Aquellas llegaron con la colonización y se establecieron como las primeras y prioritarias en el sistema educativo de Camerún, siendo estas el francés y el inglés. Por este motivo, tienen el estatuto de lenguas oficiales. Ambos idiomas son endógenos, pues si bien son extranjeros, se impusieron y se adoptaron en un contexto donde existe una diversidad etnolingüística con un sustrato cultural camerunés, pero con una fachada occidental. Ambas son lenguas de enseñanza en distintos niveles de la docencia.

En el medio de todas estas manifestaciones culturales, ¿cómo pueden nuestros alumnos desenvolverse eficazmente en clases de español que reciben, al lado de los demás idiomas que los acompañan en su vida diaria?

\section{FORMACIÓN ACADÉMICA EN UN CONTEXTO PLURILINGÜE}

Así hechas estas consideraciones anteriores, nuestros alumnos de español de la Facultad de Artes, Letras y Ciencias Humanas de la Universidad de Maroua ${ }^{8}$ tienen un itinerario escolar y académico del cual salen con una doble formación lingüística. Si bien si en Camerún, el bilingüismo institucional se hace a través del francés y el inglés, este 'bilingüismo’ es más visible en ellos mediante el español y el francés. El inglés siendo así relegado en un segundo plano, aunque el mencionado bilingüismo francés/inglés se sigue en la universidad a través de la enseñanza de una asignatura de inglés para los francófonos, en este caso, nuestros alumnos de español, y el francés para los escasos anglófonos o alumnos francófonos de cultura anglófona de la universidad. Ello se justificaría por la poca atención dedicada a la enseñanza del inglés, en el caso de nuestros alumnos, hecho reconocido, a veces, incluso por los propios docentes encargados de implementar este bilingüismo. El francés es el primer idioma con el que entran en contacto a nivel escolar. Y

8 La Facultad de Artes, Letras y Ciencias Humanas es funcional desde el año académico 2013-2014 como queda señalado. Ya desde este primer año de su funcionamiento, los alumnos del tercero de la Escuela Normal Superior acudían para sacar el diploma de ‘Licence'. Como se puede notar, va creciendo el número de nuevos alumnos de ELE matriculados cada año, de modo que en el año académico 2019-2020, el total de los alumnos de español ha crecido considerablemente, aproximando los trescientos cincuenta para los tres niveles académicos. Este número creciente también es observable en otras universidades del país, de manera que hoy por hoy, el número de los estudiosos de español en la enseñanza superior en Camerún asciende a unos tres mil y de aquí a diez años, será un efectivo susceptible de triplicar. 
hasta su ingreso en la universidad, por lo menos el 95\% de las clases que reciben se imparte en francés. Se les inculcan las primeras reglas de gramática o de aritmética en francés. Antes que en sus dialectos, el primer abecedario lo reciben en francés, al igual que las sílabas, palabras u oraciones que forman, así sucesivamente hasta construir reflexiones en torno a textos o discursos en ejercicios de disertación. En estas circunstancias nuestros alumnos llegan a convertirse en expertos en la lengua de Molière, a veces incluso hasta olvidar progresivamente sus propios dialectos.

Una vez a la hora de elegir un idioma extranjero, en el tercer curso del colegio, la mayoría no duda en seleccionar el español, por varias razones. Primero por la proximidad lingüística, siendo el francés más próximo al español por sus comunes raíces latinas. Lo cual no les plantearía muchas dificultades en varios aspectos relacionados con el aprendizaje de su nuevo idioma. Segundo, por el sitio que ha venido a ocupar España en el futbol. En efecto, los cameruneses son aficionados a este deporte, por lo que siguen casi todos los campeonatos europeos, entre otros. Por España, por ejemplo, han pasado muchos deportistas cameruneses, al ejemplo del goleador Eto'o, quien ha dejado marcas positivas en el mundo futbolístico. Ello ha contribuido a reforzar los lazos entre Camerún y España y a llevar a los cameruneses a interesarse más por este país de la península ibérica. Tercero, con la reciente explosión de la industria de las telenovelas, de cultura hispánica, mucha gente ha venido a interesarse por las historias de amores, decepciones, etc. que aparecen en ellas, donde cada televidente es capaz de identificarse fácilmente con un personaje o una circunstancia. Del mismo modo y como un efecto de moda, muchas personas dan a sus hijos nombres de algunos personajes, héroes o heroínas. Si en el punto de vista puramente académico o escolar, todos estos factores contribuyen sin duda a generar cierta simpatía de los alumnos cameruneses hacia los españoles, como bien observa Mbarga (1995: 243), esta simpatía puede incluso extenderse a la población, en general.

Una encuesta realizada por nosotros, entre noviembre de 2015 y febrero de 2016, a unos cuarenta y cinco alumnos (de ambos sexos) de los tres niveles de estudio deja constancia de esta doble conciencia orientada hacia el español y el francés. En dicha encuesta, había que enumerar por orden de interés e importancia, desde el punto de vista de los encuestados, diez elementos, a nivel internacional, sobre los aspectos siguientes: los personajes históricos, los acontecimientos históricos, los autores en literatura, las obras literarias (todos los géneros confundidos), los músicos y los platos en lo culinario. De las respuestas, muy pocas, el $5 \%$ se ha orientado hacia el mundo anglosajón, mientras que el $46 \%$ y el $49 \%$ de alumnos se han situado en las esferas culturales francesa y española, respectivamente. Lo cual se explicaría por la fuerte dosis, en los programas escolares, de aspectos relacionados con la cultura de Francia que ellos reciben hasta el nivel del bachillerato y de España, sobre todo, por la ya mencionada influencia cultural hispana que vehiculan los medios de comunicación, así como por las enseñanzas que van recibiendo en la educación superior, en las que abundan elementos culturales de los diferentes pueblos representados por la lengua en la que impartimos clase. Porque de acuerdo con Abreu Espinosa (2009: 126), los docentes nos situamos en una situación desventajosa y por lo tan- 
to fallamos en nuestros objetivos de lograr que nuestros alumnos hablen con fluidez la lengua que les enseñamos, al separar el componente cultural del lingüístico en las prácticas del aula.

La casi ausencia de datos relacionados con el mundo anglosajón en las respuestas de nuestros alumnos podría explicarse por el que estos se interesan poco por la actualidad o cultura universal, mediante el autodidactismo posibilitado a través de otros medios como lecturas personales o medios de comunicación como noticias radiofónicas o televisivas. El objetivo directo para ellos es la consecución de un futuro puesto de trabajo, en la mayoría de los casos, en la función pública donde para ingresar, harían ellos prevalecer así sus conocimientos en el reducido ámbito de su formación. De hecho, todos los alumnos, en general, están de acuerdo en que el español les ofrecería un puesto de docencia ${ }^{9}$, de traductor/intérprete, o les brindaría una oportunidad para trabajar en algún organismo internacional donde se utiliza la lengua de Cervantes. A pesar de los esfuerzos realizados por la profesionalización de la formación escolar y académica, hecho posible gracias a las exigencias del conocido sistema LMD (Licenciatura-Máster-Doctorado), introducido en Camerún y elaborado por primera vez en $2007^{10}$, este estado de cosas podría dar cuenta del fallo de un sistema educativo en el que los alumnos aún estarían condenados a restituir o a contentarse con la enseñanza que reciben y más allá de la cual carecerían competencias. Del mismo modo, la formación que reciben no está exenta de ciertas consecuencias como el olvido, a veces, de sus propias culturas.

Esta doble formación lingüística, basada en una aculturación o progresiva aculturación de los alumnos de español de la universidad de Maroua se debe, como queda señalado, a los efectos producidos en ellos por el francés, primero, y el español, segundo, instrumentos en los que se apoyan mayoritariamente para su formación escolar y académica. Esta aculturación va constituyendo, no cabe duda, una amenaza real, en la medida en que piensan en ambos idiomas. Los saberes que reciben se hacen, con prioridad, en castellano, pero a la hora de captarlo todo, el francés resulta importante. Buen ejemplo de ello es el diccionario bilingüe español/francés que manejan en clase, con el fin de buscar el significado de algún vocablo cuyo sentido se les escapa. Para asimilar mejor una palabra,

9 Desde este punto de vista, al nivel local, para limitarnos tan solo a la ciudad de Maroua, a menudo el hecho de haberse orientado hacia esta elección del español posibilita cierto acercamiento entre los alumnos de la Facultad y los de la Escuela Normal Superior (donde se forman profesores de colegios e institutos), y se crea así cierta comunidad por afinidad lingüística. Asimismo, llega a observarse cierta complementariedad entre todos ellos.

10 Inicialmente, el sistema LMD nace en los acuerdos de 1999 en Bolonia, y los objetivos eran, entre otros, la adopción de una mejor lisibilidad y comparación de los diplomas, de un sistema de créditos transferibles o la promoción de la movilidad, todo esto con la finalidad de mejorar el sistema educativo dentro de los países de la Unión Europea. Pero más tarde, se ha universalizado el concepto, y en África central, por ejemplo, han sido importantes la conferencia de rectores de la misma subregión, por una parte, y la reunión de rectores de la CEMAC (Comunidad Económica y Monetaria del África Central), por otra parte, ambas en 2003. Estos encuentros llevaron a la Declaración de Jefes de Estados de 2005 en la ciudad Libreville en Gabón. Si se consideraba la introducción del LMD como factor de la economía de estos países, es de notar, en cambio, que se han invertido pocos medios para su mejor sistematización. 
un giro o una expresión idiomática, en clase o no, el francés les resulta de interés porque se identifican mejor con esta lengua, por las razones ya evocadas. Por una parte, no todos hablan el mismo idioma materno y si fuera el caso, por ejemplo, con el fulfuldét ${ }^{11}$, no todos tienen suficientes e iguales dotes para manejarlo. O lo que es lo mismo, el fulfuldé de los alumnos que lo tengan como idioma materno tendría especificidades (la pronunciación, la entonación, la sintaxis, etc.), sin olvidar que dentro de esta misma lengua, aparecen dialectos que varían en cada una de las tres regiones de la parte septentrional de $\mathrm{Ca}$ merún (Adamaoua, Norte y Extremo-Norte).

En efecto, estamos ante un buen ejemplo de aulas donde los alumnos proceden de muchas culturas, con un grado de diferencia relativamente alto entre unas y otras. En el sentido en que algunos de los idiomas que manejan ellos encierran lazos ciertos otros por tener las mismas familias de lenguas. Por otra parte, no siempre sus idiomas maternos les ofrecen suficiente vocabulario, en comparación con el que proporciona el español o el francés, lo cual hace que esos idiomas se consideren al margen de la construcción de su personalidad dentro del marco socioeducativo en el que evolucionan. De hecho, en los idiomas maternos, a veces, se usan préstamos de palabras francesas o de origen francés, o inglés en escasos casos, a pesar de estar los alumnos de Maroua en la parte francófonaprueba de la consecuente fuerte influencia del francés en la zona. Del mismo modo, se estructura su porvenir en torno a dichos idiomas, considerados de referencia, en los que se expresarían en el marco de su futura profesión, nacional o internacional.

Esta doble formación lingüística se construye dentro de cierto bilingüismo, aunque con rasgos específicos, pues, es un bilingüismo distinto del conocido en la parte anglófona del mismo país, o en España, por ejemplo. Como se ha visto anteriormente, el español y el francés son los dos idiomas que posibilitan este bilingüismo de nuestros alumnos de Maroua, a través de un mecanismo de interactuación y compenetración. Es importante señalar, para concordar con Saussure (1995: 109), que cada lengua representa una cultura, con sus especificidades. Una palabra puede revestir significados duales de los que carecería en otra lengua. Del mismo modo, el fenómeno de alteración de una palabra puede variar de una lengua a otra, dificultando así el sentido de palabras que creemos captar fácilmente. Ya que, como opina Coseriu (1986: 70), “los signos que encontramos en un sistema en un momento dado, pueden haber pertenecido antes a otros sistemas (a otras comunidades sociales), lo cual a menudo nos explica las particularidades que pueden presentar en su forma o en su significado". Pueden multiplicarse casos parecidos, en distintos niveles de un discurso, también a través de interferencias lingüísticas como préstamos, calcos, sin olvidar los casos de falsos amigos... Cada concepto, dentro de una lengua precisa, conlleva una carga semántica y evolutiva propia, incluso dentro de lenguas que

11 Lengua hablada por los fulanis o peul, procedentes del África del oeste, que sometieron, a partir de finales del siglo XIX a la zona correspondiente a las actuales tres regiones del norte de Camerún. Por lo que hoy en día, esta es la lengua materna de los musulmanes de esta zona. Sin embargo, por su uso en una zona bien larga y su carácter práctico de comunicación entre diferentes tribus, la hablan también los pue blos kirdis que se habían resistido a dichas invasiones y se habían recluido en zonas montañosas. 
tengan un mismo origen como es el caso con el español y el francés. Por lo que en opinión de Abreu Espinosa (2009: 128), lo adecuado sería lograr instalar entre los aprendices una competencia comunicativa ${ }^{12}$ basada en el aspecto intercultural. En cierta medida, este estado de cosas pone en el tapete la problemática de la adecuación de los manuales escolares al contexto español. Porque como piensa Manga (2009: 28), la estancia de muchos docentes por España les ha permitido actualizar sus conocimientos sobre la percepción que a través de los manuales tenían del mismo país. Como consecuencia se puede notar una mejora significativa entre los actuales y los anteriores en la enseñanza secundaria (Kem-Mekah Kadzue, 2014: 271-272), manuales en los que también se han apoyado nuestros alumnos de Maroua.

No hemos de olvidar que, en ocasiones, algunas asignaturas facilitadas por el programa escolar contribuyen a reforzar de manera significativa este bilingüismo español/francés. Es el caso de la traducción, del español al francés y viceversa, todavía considerada como una de las vías por excelencia de construcción y adquisición del vocabulario y otras competencias lingüísticas. Si, por ejemplo, el método tradicional de la enseñanza se focalizaba tan solo en la traducción para medir el grado de competencia lingüística de los aprendices, hoy en día, los llamados métodos activos incitan a cierta espontaneidad comunicativa por parte del alumno, sin que este necesite forzosamente recurrir a una lengua primera, el francés en este caso. No es superfluo señalar que los objetivos preconizados por los nuevos métodos de enseñanza siguen tardando en concretarse eficazmente. Porque nuestros alumnos aun se sitúan en la esfera de una especie de condena a recurrir al francés, mediante una gimnasia interiorizada consistente ora en pensarlo todo en la lengua primera antes de plasmarlo en la lengua 'extranjera', como solemos ver en tareas de disertación literaria en que por lo común lo escriben en francés en el borrador antes de transcribirlo al español; ora en tratar de asimilar sus clases de español, impartidos asimismo en español, pero pensando y relacionándolo con el francés. Por supuesto, este ejercicio no es exento de algunas trampas debidas a las especificidades de cada lengua como hemos tenido la oportunidad de mencionarlo arriba. Todo lo expuesto nos lleva a esbozar unas propuestas para mejorar las competencias comunicativas por parte de nuestros alumnos de ELE.

\footnotetext{
12 El concepto de competencia comunicativa no sabría entenderse al margen de la competencia lingüística que reviste una amplia significación. La definición que le ofrece a esta última Carzon (Véase Belinga Bessala, 1996: 25-26) nos parece mejor explicitada, en el sentido en que abarca otras competencias que debe seguir el alumno a la hora de aprender una lengua extranjera. Por ejemplo, son seis los elementos que deben tomarse en consideración: primero la facultad para mejor usar e interpretar la lengua en cuestión, en un plano general; segundo, la facultad para mejor usar e interpretarla en una determinada situación, lo cual hace referencia a la sociolingüística; tercero, la habilidad de percibir y realizar la coherencia de oraciones en contextos de significación (competencia discursiva); cuarto, la habilidad y empatía de aprender situaciones sociales involucradas en la comunicación (competencia social); quinto, la adecuación y familiaridad del hablante en un contexto sociocultural (competencia sociocultural) y, por último, la habilidad de usar estrategias verbales y no verbales para compensar las lagunas en el conocimiento del código de la lengua del usuario (competencia estratégica).
} 


\section{ALGUNAS REFLEXIONES DE CARA A UNA MEJOR ADQUISICIÓN DE COMPETENCIAS COMUNICATIVAS EN ESPAÑOL}

El contexto globalizado actual, por ser cada vez más competitivo, incita a tener más exigencias en todo lo relacionado con la formación, desde la concepción de los programas hasta su implementación en las aulas, y son conscientes de ello los encargados de llevar a cabo las políticas educativas en Camerún ${ }^{13}$. Se trata, en efecto, de una competición a la que además de estar preparado en el terreno ajeno, hay que aportar también lo suyo propio. Es una cita del dar y del recibir, en que valen tanto lo exógeno y lo endógeno, y desde este punto de vista hay razones para señalar que los alumnos de español de la Facultad en Maroua van menos preparados. En la práctica, su bilingüismo español/francés, que es una riqueza inconmensurable, sería más ventajoso, con tal de conseguir más equilibrio entre ambas lenguas. Asimismo, con la introducción de una asignatura optativa de español desde la enseñanza primaria, aunque fuera una hora semanal, como ya es el caso a partir del tercer curso en la secundaria, los alumnos, al llegar a la universidad, tendrían más vocabulario y otras competencias; todo ello con el espíritu de seguir fomentando lo local y, en este sentido, son muy loables los esfuerzos que se realizan en la paulatina introducción de más idiomas maternos en el sistema educativo. A nuestro modo de ver, esta situación reforzaría más las competencias expresivas y comprensivas de nuestros alumnos de español, lo cual les proporcionaría más visibilidad a nivel internacional. Porque sin tener la pretensión de descreditar los conocimientos que ellos van adquiriendo, es posible, en las condiciones actuales, que un alumno graduado no pueda ofrecer indicios satisfactorios con sus compañeros de otras universidades en el mundo.

Si en la mayoría de los casos les achacamos la culpa a nuestros alumnos de esforzarse poco o menos, es de notar que las responsabilidades también pueden situarse en niveles más altos. En este sentido, es importante señalar los escasos medios materiales invertidos en la enseñanza superior para una formación continua de los docentes, lo cual tiene incidencias en los resultados de los alumnos, o el insuficiente acento puesto en la profesionalización de la enseñanza ${ }^{14}$, con el objetivo de garantizar un empleo a cada alumno; la fal-

13 El ministerio de la enseñanza superior de Camerún, en 2010, ha elaborado un documento (06/231/MlNESUP del 16 de mayo del mismo año), con el fin de crear órganos para la implementación efectiva del LMD. Desde entonces, se han organizado varios encuentros sobre el aspecto.

14 En la profesionalización de la enseñanza, han de tomarse en cuenta una serie de retos: los académicos (armonización de los aspectos curriculares a nivel global), pedagógicos (apoyarse en los métodos nuevos de enseñanza/aprendizaje), infraestructurales (construcción de bibliotecas, mediatecas, pinacotecas, laboratorios adecuados...) y de la gobernanza (más rigor en la gestión de recursos humanos y materiales, etc.). Todo ello debe tomarse en cuenta para una mejor profesionalización de nuestro sistema de la educación superior. Pero en el terreno, ¿cuántas infraestructuras adecuadas aparecen, para tomar solo el caso de la universidad de Maroua, donde nuestros alumnos carecen de sitio propio y reciben así clases en condiciones difíciles, en aulas que no cumplen los requisitos, por faltar sitios, salubridad o aeración, entre otras cosas? No tienen acceso a la documentación por la falta de bibliotecas donde puedan tener acceso a manuales. En estas condiciones, no suele sorprender que algunos alumnos confiesen no haber tocado nunca un libro original editado en español, durante tres años de estudios universitarios, pues, sólo se contentan con manejar algunas copias sueltas. Y su poder adquisitivo está muy lejos de ofrecerles otras posi- 
ta de existencia, de manera oficial, de programas armonizados para los alumnos de ELE de todas las universidades de Camerún. La consecuencia directa son las formaciones diferentes que ellos reciben. Uno de los problemas que esto plantea es el de la transferibilidad de créditos, porque a un alumno de español, de la Facultad de Artes y Letras de la universidad de Maroua que haya capitalizado sus ciento veinte créditos de los dos primeros cursos, y que quiera seguir sus estudios en otra universidad del país, se le exigirá sin duda que repita algunas asignaturas, si no es todo el segundo curso, con el fin de situarse al mismo nivel de los alumnos de la nueva universidad en cuestión. Para una efectividad del sistema LMD, urge una armonización de los módulos de enseñanza en las universidades de Camerún. Además, deben trabajar los actores en el sentido de mejorar las condiciones de trabajo. Si todos estos criterios no están reunidos, nuestros alumnos siempre estarán limitados y condenados así a evolucionar al margen de la globalización que, en realidad, ofrece un abanico de oportunidades.

Una formación sólida en lenguas extranjeras requiere un mejor manejo del idioma, no sólo al nivel de la escritura, la lectura o la escucha sino también en la práctica. Desafortunadamente, parece insuficiente el tiempo dedicado a actividades prácticas en nuestras aulas universitarias. Para suplir esta carencia, los docentes deben insistir mucho más en el enfoque comunicativo, poniendo así a los alumnos al centro de las actividades didácticas. Lo cual requiere aptitudes por parte de los propios educadores que carecen, las más de las veces, dotes para la organización y selección de saberes que potencian las competencias lingüísticas, como apunta Belinga Bessala (1996: 132). Es más, la competencia comunicativa va más allá de las lingüísticas ya que como señalan Essome Lele y Hatolong Boho (2019: 194), citando a Melero Abadía, es "el fluir de varias destrezas o subcompetencias que se interrelacionan”. Deben multiplicarse actividades prácticas como son exposiciones escritas y orales, individuales y en parejas o en grupos, en las que se velará en la organización y la claridad de ideas. Por eso, ya no deben considerar a los alumnos como receptáculos, en quienes hay que verter enormes cantidades de conocimientos teóricos durante largas horas. El alumno debe sentirse en confianza y ser actor en la construcción de sus conocimientos.

En la historia de la didáctica, han existido tres tendencias fundamentales centradas respectivamente en el profesor, en los contenidos y en el alumno. La primera sitúa al do cente al centro de las actividades, por lo que es el detentor exclusivo e indiscutible de los conocimientos. Es omnisciente y todopoderoso, frente al alumno que es un mero receptáculo. En este sentido, el aprendiente es considerado un eterno ignorante y depende, por lo tanto, de su maestro. En la segunda tendencia, se pone énfasis en los contenidos. Por eso, se piensa que el éxito del alumno depende de la cantidad de informaciones puestas a su alcance. En consecuencia, esto termina aburriéndolo ya que, en definitiva, no retiene

bilidades como es el uso de libros electrónicos que necesita poseer previamente un soporte. A propósito del impacto negativo, por la falta de infraestructuras adecuadas, en las competencias de los alumnos de español de la Universidad de Maroua, consúltese a Toumba Haman (2018). 
mucho de lo que tiene. La última tendencia es considerada como la más operativa, por cuanto coloca al alumno al centro de su formación. El alumno participa en su propia formación, aprendiendo a construir los saberes que le parezcan más adecuados. Se trata de la autonomía en el aprendizaje. Pero antes, el alumno debe ser consciente de sus lagunas. Un tal hecho puede entonces despertar en él más curiosidad para aprender por sí solo y mejorar su expresividad. Por eso, en los tiempos libres como en el recreo, los alumnos deben hablar entre sí en español y no en otras lenguas como solemos observar. En estas palabras de Montes Mozo (2004: 11-12), leemos bien algunos factores que facilitan la comunicación entre nuestros aprendientes de lenguas extranjeras, cuando apunta que:

la habilidad comunicativa como la respuesta efectiva a una situación de relación interpersonal, puede ser favorecida, como las demás habilidades, con estímulo, información y métodos de trabajo específicos y ocasiones de continua práctica, que debe facilitar el profesor, y que se hacen más necesarios cuando la interacción se realiza entre individuos que no comparten la misma lengua y la misma cultura, ya que una premisa para la comunicación es que los interlocutores dispongan del mismo código o de códigos parecidos y compartan conocimientos previos que no están contenidos en el acto de habla sino que se presuponen.

Además de la labor profesional del docente, los alumnos deben recurrir a otras actividades fuera del aula. Con las facilidades que brindan los medios de información, cada vez más asequibles hoy en día, nuestros aprendices, con la finalidad de mejorar sus habilidades comunicativas para así competir a nivel internacional, deben ser más responsables aprendiendo de manera autónoma. Ya que es muy insignificante el tiempo dedicado para las clases en el aula universitaria y eso, ya desde la enseñanza secundaria. Lo cual se entiende mejor a partir de la siguiente interrogación de Kem-Mekah Kadzue (2016: 99): “¿Por qué después de cinco años aprendiendo español el alumno camerunés es incapaz de mantener una conversación en español?’. La mayoría de nuestros alumnos, incluso después de adquirir el diploma de 'Licence', tras tres años de estudios superiores, siguen teniendo muchísimas dificultades para entablar una buena conversación en español. Una solución a este problema es el autoaprendizaje y la autoevaluación a los que han de someterse. Por eso y de manera permanente, deben mirar películas y programas variados, escuchar audios de clases, libros, canciones y otras actividades que les propicien conocimientos para mejorar sus habilidades comunicativas a través de una correcta escucha, lectura y actividades oral y escrita. Para mejor integrarse en la comunidad hispánica mundial, deben adquirir estas competencias que son esenciales para su afirmación.

\section{CONCLUSIONES}

En definitiva, la presente reflexión se ha centrado en la problemática de la doble formación linguística, basada en el español y el francés, de los alumnos de la Facultad de Artes, Letras y Ciencias Humanas de la Universidad de Maroua, específicamente. Si muchos de 
ellos son capaces de manejar varios idiomas maternos, en determinados grados, en cambio, es de interés señalar que no piensan, desafortunadamente, en dichos idiomas. Lo atestiguan las diferentes interferencias léxicas y sintácticas muy frecuentes en sus prácticas académicas. Todos se identifican así con el francés, por proceder de la zona francófona y por el lugar importante que ha venido teniendo este mismo idioma a lo largo de su formación escolar, hasta el nivel del bachillerato. Sin embargo, el español, por haberse orientado ellos hacia estudios hispánicos en la enseñanza superior, ocupa un lugar determinante en su vida, en la medida en que casi todos sueñan con tener un futuro empleo en el que vayan a poner en práctica lo estudiado. Junto con el español, el francés viene a ocupar así un sitio no menos preponderante, en la medida en que se identifican con él, como anteriormente apuntado. Y lo notamos en las prácticas de clase, donde recurren mucho a este idioma para mejor entender sus apuntes de español.

Así entendido, el español y el francés estructuran la personalidad de nuestros alumnos, a pesar de los esfuerzos llevados a cabo, como recomiendan los nuevos métodos de enseñanza de una lengua extranjera, para que ellos no recurran a una primera lengua, el francés en este caso, a la hora de adquirir competencias comunicativas. De ahí que hayamos hecho propuestas con vistas a mejorar el sistema educativo camerunés que tarda todavía en la puesta en práctica de algunas de las recomendaciones del sistema LMD, en vigor en muchos países del mundo, paradigma idóneo para el acercamiento y la preparación del alumno a su futuro trabajo en la sociedad. Del mismo modo, sería importante dejarles más autonomía y margen de maniobra a los actores del sistema educativo, en quienes suele planear la sombra de los políticos. Además de dedicar más espacio a actividades comunicativas en el aula, una mejor adquisición de competencias comunicativas por parte de nuestros alumnos debe pasar necesariamente por su autoaprendizaje y autoevaluación, mediante la sarta de actividades audio y vídeo que ofrecen los medios de comunicación.

\section{REFERENCIAS}

ABREU ESPINOSA, Y. (2009): “Lengua y cultura: componentes esenciales en la comunicación'. En Islas, Revista de la Universidad Central 'Marta Abreu' de las Villas, Cuba, 159, pp. 126-131.

BELINGA BESSALA, S. (1996): Didáctica aplicada a la formación del profesorado y a la enseñanza del español como lengua extranjera. Madrid: Lothan.

COSERIU, E. (1986): Introducción a la lingüística. Madrid: Gredos.

ESSOME LELE, G. A. y HATOLONG BOHO, Z. (2019): “Enseñanza/aprendizaje del español/LE en la secundaria camerunesa desde una estrategia glotodidáctica endógena para el desarrollo de la competencia”. En Revista de Educación, Año X, 17 pp. 187202, [en línea] [Enlace]. 
GIRY, M. (2002): Aprender a razonar. Aprender a pensar, Traducción de Glenn Gallardo. México-Argentina: Siglo XXI editores.

KEM-MEKAH KADZUE, O. (2016): Enseñanza y aprendizaje del español en Camerún: análisis de las creencias alumnado/profesorado e implicaciones didácticas para una formación competitiva de estudiantes/docentes de ELE. Tesis doctoral, Universidad de Lleida.

(2014): "La enseñanza/aprendizaje del español en Camerún: el discurso ideológico y la problemática de los manuales didácticos". En Centro Virtual Cervantes, pp. 363-374, [en línea] [Enlace].

LAWO-SUKAM, A. (2014): “Hispanismo en África subsahariana más allá de la colonia: una aproximación a la literatura hispano-camerunesa". En Revista Iberoamericana, Vol. LXXX, 248-249, pp. 899-917, [en línea] [Enlace].

LÓPEZ REYES, F. (2009): “Técnicas para enseñar a pensar y métodos de aprender a aprender”. En Educativa, Revista Digital, 15, pp. 1-9, [en línea] [Enlace]

MANGA, A. M. (2009): "Incidencias de los factores afectivos en la enseñanza/aprendizaje de una lengua extranjera: caso de la situación del Español en Camerún”. En Ogigia: Revista electrónica de estudios hispánicos, 5, pp. 19-28, [en línea] [Enlace].

MANGA, A. M. y GARCÍA PAREJO, I. (2007): "Las prácticas educativas en las aulas de ELE en Camerún: cómo acercar las necesidades comunicativas al contexto africano". En La situación actual del español en África. Actas del II Congreso Internacional de Hispanistas en África. Madrid: Sial/Casa de África, pp. 232-242.

MBARGA, J.-C. (1995): “Enseñanza y aprendizaje del español en Camerún: el caso de la enseñanza media”. En Revista de Lenguaje y Textos, 6 y 7, pp. 243-247, [en línea] [Enlace]

MONTES MOZO, C. (2004): "Facilitar la adquisición y el desarrollo de la habilidad comunicativa, un reto para el profesor de lenguas extranjeras". En Habilidades comunicativas en las lenguas extranjeras. Madrid: Ministerio de Educación y Ciencia, pp. 926, [en línea] [Enlace].

NANA TADOUN, G. M. (2016): “Otras literaturas de expresión española: África entre francofonía, anglofonía e hispanidad”. En Letralia, Tierra de Letras, [en línea] [Enlace].

NGUEPI, G. V. (2007): “Interferencias lingüísticas y variedades dialectales en la enseñanza del español como segunda lengua en un contexto africano: caso de Camerún”. En Tonos digital, Revista electrónica de estudios filológicos, 14, [en línea] [Enlace]. 
ONOMO-ABENA, S. (2014): "La enseñanza de la lengua y literatura españolas en Camerún en la educación secundaria y universitaria”. En Javier Serrano Avilés (Coord.), Enseñanza del español en África Subsahariana. Madrid: La Catarata, pp. 176-190, [en línea] [Enlace].

ORTIZ FONSECA, M. (2011): Competencia comunicativa en el aula universitaria. Bogotá: Editorial Universidad del Rosario.

ROUSSEAU, J.-J. (1966): Emile ou de l'éducation. Paris: Flammarion.

SAUSSURE, F. de (1995): Cours de linguistique générale. Paris: Payot et Rivages.

ST-YVES, A. (1982): Psychologie de l'apprentissage-enseignement. Une approche individuelle ou de groupe. Canada: Presses Universitaires du Québec.

TOUMBA HAMAN, P. (2018): “La incidencia de los problemas infraestructurales en las actividades de enseñanza-aprendizaje del E/LE en los alumnos de la FALSH de la Universidad de Maroua: unas estrategias didácticas”. En Zacharie Hatolong Boho y Gilles Kuitche Talé (Coords.), Enseignement, diffusion et ancrage social des langues étrangères au Cameroun: histoire, enjeux et perspectives. Yaoundé: Proximité, pp. 185-201. 